\title{
COMMENTARY
}

\section{Immersive Research Experiences for High School Students Aimed at Promoting Diversity and Visibility in Pharmacy Education}

\author{
Jacqueline E. McLaughlin, PhD, MS, Antonio A. Bush, PhD, Adam D. Friedman, PhD, MA, \\ Samuel K. Lai, PhD \\ University of North Carolina at Chapel Hill, UNC Eshelman School of Pharmacy, Chapel Hill, North Carolina \\ Submitted March 7, 2019; accepted September 25, 2019; published March 2020.
}

\begin{abstract}
Two challenges frequently faced by schools of pharmacy are the training of a workforce that reflects the racial and ethnic diversity of the populations they serve, as well as raising public awareness of the mission and impact of pharmacy schools. One underutilized strategy in addressing these challenges is directly engaging high school students, whose race and ethnicity more closely reflect the increasing diversity of the US population, in immersive research experiences at schools of pharmacy. Motivated by the multidisciplinary nature of pharmaceutical sciences that involve integration of various science, technology, engineering, and mathematics (STEM) disciplines, the UNC Eshelman School of Pharmacy created the Young Innovators Program (YIP). The program is an eight-week paid summer internship that immerses participants in cutting-edge and innovative research. Through careful planning, strategic collaboration, and a purposeful recruitment process, we believe pharmacy education could benefit from the expansion of immersive programs that promote the engagement of racially and ethnically diverse high school students in real-world research.
\end{abstract}

Keywords: research, diversity, high school, pharmaceutical sciences, pipeline

Demographics in the United States are quickly shifting. Census population projections have underscored current racial minorities as the primary demographic driving the nation's growth. ${ }^{1}$ Projections suggest that, by the year 2045, the racial/ethnic make-up of the nation will no longer be "majority White," as individuals self-identifying as White will comprise only $49.7 \%$ of the population, in contrast to $24.6 \%$ Hispanic and Latin*, $13.1 \%$ African American and Black, 7.9\% Asian, and 3.8\% multiracial groups. ${ }^{1}$ Thus, in 2045 , the racial and ethnic diversity of the US population will be greater than at any other time in the nation's history. ${ }^{1}$

A common mission for schools of pharmacy is to enroll and educate a workforce that can meet current and future healthcare demands of the country's quickly shifting demographics. ${ }^{2,3}$ Research suggests that patient trust in practitioners can vary significantly across race and

Corresponding Author: Jacqueline McLaughlin, UNC

Eshelman School of Pharmacy, University of North Carolina at Chapel Hill, Chapel Hill, NC 27599. Tel: 919-966-4577. E-mail: Jacqui_mclaughlin@unc.edu.

Note: At the time of manuscript submission, coauthor Dr. Bush was affiliated with UNC Eshelman School of Pharmacy. Dr. Bush is now with the Association of American Medical Colleges in Washington, DC and holds an adjunct faculty position at UNC. ethnicity, with racial concordance in the patient-provider relationship influencing patient satisfaction, communication, and intention to adhere to treatment. ${ }^{4-7}$ In addition, health disparities (ie, preventable differences in health or health care experienced by socially disadvantaged populations) disproportionately affect medication access, prescriptions, and adherence among some groups, such as African Americans and Hispanics. ${ }^{8,9}$ As such, it is critical that educators and learners are equipped to understand, identify, and prevent barriers to medication access, prescriptions, and medication adherence among minoritized groups.

While these challenges highlight the importance of increasing the representation of racially minoritized students in pharmacy schools, efforts often fall short of meeting the longstanding ideal of developing a workforce that reflects the same racial and ethnic diversity as the populations they serve. ${ }^{10}$ As such, there is an expanding body of literature supporting the need for greater diversity and inclusion in pharmacy and health professions education, and the infrastructure changes necessary to support greater inclusion among the student body. ${ }^{11-13}$

Schools of pharmacy draw most applicants from undergraduate institutions in the United States. ${ }^{14}$ Therefore, efforts to broaden student diversity within pharmacy schools often include targeted recruitment efforts at the 


\section{American Journal of Pharmaceutical Education 2020; 84 (3) Article 7589.}

undergraduate level. However, the racial/ethnic profile of undergraduate students at historically White institutions often differs from its state population. Using the state of North Carolina and University of North Carolina at Chapel Hill (UNC-CH), for example: the 2017 census shows that the population of the state is approximately $70 \%$ White, 22\% African-American and Black, 10\% Hispanic and Latin*, and 3\% Asian. ${ }^{15}$ However, the racial distribution of undergraduate students at UNC-CH is $66 \%$ White, 18\% Asian, 11\% African-American, and 9\% Hispanic. ${ }^{16}$ Unsurprisingly, the racial distribution of the incoming students at the UNC Eshelman School of Pharmacy in 2018 (62\% White, 24\% Asian, 10\% African American and Black, and 5\% Hispanic and Latin*) more closely reflected UNC-CH's undergraduate population than the North Carolina population at large. ${ }^{17}$ These realities are pervasive across a diverse array of disciplines offering advanced degrees, and there have been substantial efforts to increase racial and ethnic diversity through changes to recruitment strategies. ${ }^{18-20}$

In our view, unless the student demographics of the undergraduate institutions that pharmacy schools draw upon are reflective of the general population, or pharmacy schools implement strategic practices to authentically recruit from diverse student pools (eg, Historically Black Colleges and Universities (HBCUs), Minority Serving Institutions), it is unlikely that the demographics of pharmacy students will reflect the same racial diversity of the populations they serve. In addition to the aforementioned strategy, we believe pharmacy schools may benefit from strategic efforts drawing pre-college students (ie, high school) to the profession in order to broaden racial/ ethnic diversity. In fact, recent research suggests that early exposure to health professions and pipeline programs targeting students identifying as racial and ethnic minorities plays a key role in exposing them to career paths, affording them opportunities to gain skills through real-life experiences, and better informing or affirming their career decisions that may last a lifetime, regardless of the profession they choose. ${ }^{21}$

There is already precedence for pipeline programs that involve high school students in activities at schools of pharmacy. For example, the University of Illinois at Chicago hosts an eight-week summer high school pharmacy enrichment program consisting of academic and experiential activities focused on pharmacy practice. They found that a large fraction of participants were influenced/motivated to pursue pharmacy as a career. ${ }^{22}$ This coincided with an increase in underrepresented students from $9 \%$ to $15 \%$. Similarly, Xavier University, an $\mathrm{HBCU}$, hosts several pipeline programs for underrepresented minorities (URM), including a year-round Student
Enrichment Program to expose prospective students to pharmacy career experiences and develop a pipeline of high-quality secondary school students derived from the local community. ${ }^{23,24}$ At the UNC Eshelman School of Pharmacy, several programs have been established to increase diversity for exposure and exploration on the high school level such as the LEAD Program and the Leadership Academy. ${ }^{24}$ We believe that increasing efforts to intentionally engage a diverse body of students prior to undergraduate study may directly increase the number of racially minoritized undergraduate students interested in careers in pharmacy and pharmaceutical sciences.

Motivated in part by the aforementioned programs, the UNC Eshelman School of Pharmacy, through the newly established Eshelman Institute of Innovation, launched the Young Innovators Program (YIP). ${ }^{25,26}$ Somewhat distinct from the aforementioned programs, YIP is an eight-week non-residential paid summer internship that provides high school students with the opportunity to immerse in cutting-edge and innovative research in science, technology, engineering, and mathematics (STEM) disciplines as they relate to the pharmaceutical sciences. The YIP participants are assigned to specific laboratories or research groups, and interns work directly under the mentorship of faculty members and graduate students who challenge them to become valuable contributors in a real-world setting. The interns also participate in a variety of career panel discussions, tour biotechnology companies and medical center facilities, and engage with the undergraduate admissions office at UNC-CH. The overarching goal of YIP is to expose students to the possibilities of addressing real world problems and contributing to novel findings through research, clinical practice, and education, and in the process, peak their interests in future careers in pharmacy and the pharmaceutical sciences.

The YIP program was launched in the summer of 2016 (details of the first cohort are previously described elsewhere). ${ }^{25}$ In 2017, 24 high school students were selected from 86 applicants using an application review and interview process. The distribution of the participants aligned more closely with the state demographics than the university's or school's demographics, with $54 \%$ of participants identifying themselves as White, $37 \%$ as an URM (ie, self-identifying as Black or African American, American Indian and Alaska Native, Hispanic and/or Latin*, and/or Native Hawaiian and other Pacific Islander), and $8 \%$ as Asian.

A survey evaluation of the program indicated that YIP participants were challenged intellectually $(100 \%$ agreed) and highly valued what they learned (96\% 


\section{American Journal of Pharmaceutical Education 2020; 84 (3) Article 7589.}

agreed). More specifically, URM participants indicated that their experience in YIP improved their knowledge in STEM (100\%) and positively influenced their desire to pursue a STEM career (89\%). Students' comments included: "My main goal is trying to find out exactly what I want to do, and I think that coming here I've learned so much about careers, and the options that are available," and "I loved the tours and the discussion panels, as we got to explore the career options in pharmacy." All participants indicated that they would recommend a friend or family member to participate in YIP (100\% agreed). ${ }^{26}$

While potentially increasing interest in pharmacy and pharmaceutical science careers among URM populations is an ambition of YIP, one of the primary aims is to increase public awareness of schools of pharmacy. Schools of pharmacy are often strongly associated with training retail pharmacists, as opposed to pioneering innovations across a continuum spanning from drug discovery, drug development, drug dosing, clinical trial design and execution, to policy and pharmacoeconomics. Further, pharmacy schools have experienced a precipitous drop in applications over the past 10 years. ${ }^{27}$ By exposing student interns to and providing them with basic research training within a burgeoning research enterprise and returning them to their communities, they serve as spokespeople capable of describing the multifaceted roles that pharmacy schools play in the nation's healthcare infrastructure and the evolution of its processes. As a reflection of the effectiveness of this public outreach, YIP application numbers increased four-fold within a single year, with more than 300 high school students applying for the program in 2018. Furthermore, applications originated not just within the state but from surrounding states and other countries.

Efforts to further evaluate and improve YIP are ongoing. Next steps in evaluation of the program will include soliciting the perceptions and experiences of the school faculty members, students, and staff members supporting YIP. Additional analyses will be used to better leverage school and university resources for promoting and supporting the program. Because graduates of the YIP program are still too young to matriculate into professional or graduate programs, longitudinal evaluations are planned to explore the educational and career pathways of these students over time. These evaluations will better position the program to sustainably provide opportunities for students with hands-on research experience while learning about future careers within pharmacy and the pharmaceutical sciences.

Despite the possible upside, implementing an immersive experience program like YIP for high school students is not without substantial challenges. First, there must be faculty commitment and buy-in of the program goal, as faculty participation and support is integral to program participants obtaining meaningful experiences. Second, substantial institutional investments are required, including provisions for personnel with the appropriate skillsets, motivation, and autonomy to develop, implement, and market the program. Third, and related, school leadership must support the initiative through both the allocation of resources (eg, faculty time, budget dollars) and a steadfast emphasis on equity, diversity, and inclusion efforts. Designing a program that aligns with the strategic vision and mission of the school and its leadership team can help foster support, commitment, and sustainability. Fourth, to overcome socioeconomic barriers that may limit access to the program for some students, it may be beneficial to allocate provisions that provide stipends to program participants, despite various institutional, state, and federal regulations that may make it challenging to administer such stipends in a manner consistent with the broadly inclusive goals of the program.

In light of our experiences with YIP and current challenges facing the pharmacy academy, we offer the following recommendations:

Recommendation 1: Pharmacy schools must take a more active role promoting pharmacy and pharmaceutical sciences among prospective students. We believe that programs like YIP can stimulate interest in STEM programs and highlight educational and career opportunities for young learners while raising the visibility of pharmacy schools within the local community, including the expanding role that pharmacists and pharmaceutical scientists play in developing new treatments and shaping the overall healthcare landscape. Raising awareness and visibility of our academy is particularly important given the continued declines in applications amid rising matriculation in pharmacy and may help attract a more racially and ethnically diverse pool of applicants to schools.

Recommendation 2: When designing a program to incorporate students from racially and ethnically diverse backgrounds, first address the types of challenges that underrepresented students face in pursuing higher education. Research suggests that students from underrepresented groups are disproportionately disadvantaged concerning access to and socialization within institutions of higher education. ${ }^{28-31}$ Incorporating strategies to address these challenges within the program and advocating for solutions to these challenges as part of the program could help garner additional support for creating actionable solutions that help students achieve success prior to and within pharmacy and pharmaceutical sciences. For example, providing stipends for students who would typically use the summer months to work. 


\section{American Journal of Pharmaceutical Education 2020; 84 (3) Article 7589.}

Recommendation 3: Equip pharmacy educators and program personnel with tools to engage in conversations about the current and historical challenges faced by minoritized and underserved groups. Program leadership should recognize that there can be palpable sociopolitical tensions prevalent across the campus and/or in communities that may lead to contentious conversations about equity, diversity, and inclusion.

Conversations about equity, equality, access, visibility, and resources, among others, should arise during program design and implementation. In an audit of one university's campus racial climate, Harper and Hurtado asserted that, "race remained an unpopular topic and was generally considered taboo in most spaces, including classes other than ethnic studies." ${ }^{\text {"32 }}$ Because racial tension is embedded in the country's history as well its colleges and universities, program developers and stakeholders must recognize, embrace, and engage in conversations that may require team members to step out of their comfort zone.

Recommendation 4: Program personnel should consider strategically targeting, engaging, and forming partnerships with select high schools and key stakeholders who serve, advocate for, and understand the experiences of racially/ethnically diverse students. The recruitment and selection process is central to the success of any pipeline program. Program leadership can work with the school or university human resources to understand the laws and regulations affecting identification of diversity in the selection process, particularly in cases when participants are payed as employees (eg, stipends). In cases where appropriate, the selection process may be enhanced through completion of implicit bias training by program personnel, particularly application reviewers, to enhance cultural awareness.

Recommendation 5: Clearly state the mission and vision for the program and make sure it is agreed upon by all participants and communicated consistently. Subsequently, the purpose, recruitment process, selection criteria, and curriculum should be aligned with one another and with the mission of the program. When encompassing equity, diversity, and inclusion as a core mission, sustained success in recruiting and admitting a racially diverse cohort of participants will require an explicit and intentional focus on diversity. Pharmacy educators and leadership should be prepared, considering this challenge, to highlight the alignment and benefits of the program for the institution, school/college, profession, and most importantly, the STEM and healthcare community.

Recommendation 6: Identify individuals willing to use their access, influence, and privilege as capital to advocate and support the program. While several models of allyship exist, allies generally take on struggles as their own, stand up on key issues, and transfer the benefits of their privilege to those who lack it. ${ }^{33,34}$ In the context of potential strategic engagement and collaboration with racially minoritized groups, this allyship can promote the effectiveness and success of such programs because it can help create buy-in from faculty members willing to devote their time and scientific expertise. Opportunities to create networks and relationships among key stakeholders committed to the success of the program could help further promote the development of the program.

\section{CONCLUSION}

Pharmacy education must play a more active and intentional role in promoting access to, interest in, and preparation for professional and graduate pharmaceutical sciences education among the full spectrum of students that reflect the same racial and ethnic diversity as the populations they will eventually serve. Pharmaceutical sciences involve the integration of multidisciplinary STEM disciplines that in turn can impact the health of millions, and thus present a highly intriguing opportunity to not only promote STEM interests but also attractive career opportunities, especially to underrepresented students in their formative high school years. Thus, in addition to programs that primarily emphasize pharmacy practice, research-intensive immersive programs in schools of pharmacy that strategically target underrepresented high school students, as exemplified by YIP and other high school immersive experience programs, likely serve as promising avenues to meet some of the unmet diversification and public outreach needs for schools of pharmacy. Finally, we believe similar platforms to YIP may help address the precipitous drop in applicants faced by many pharmacy schools by broadening interests in various career opportunities in pharmacy.

\section{ACKNOWLEDGMENTS}

The authors acknowledge all the individuals who have contributed to the design, implementation, and evaluation of the YIP program. This includes, but is not limited to Mieke Lynch, Josh Corbat, Jimmy Xu, Cody Close, Cole Barnhardt, Carlos Melendez, and Janice Anderson. We also thank the UNC Eshelman School of Pharmacy students and faculty members for creating meaningful research experiences for YIP participants. The YIP is funded, in part, by the Eshelman Institute for Innovation and Burroughs Wellcome Fund. The views presented in this commentary belong to the authors alone and do not represent the views of any YIP funders. 


\section{American Journal of Pharmaceutical Education 2020; 84 (3) Article 7589.}

\section{REFERENCES}

1. Fey WH. The US will become minority white in 2045 , Census projects. Brookings Website. https://www.brookings.edu/blog/theavenue/2018/03/14/the-us-will-become-minority-white-in-2045census-projects/. Updated March 14, 2018. Accessed March 6, 2020. 2. Echeverri M, Brookover C, Kennedy K. Nine constructs of cultural competence for curriculum development. Am J Pharm Educ. 2010;74(10): 181 .

3. O'Connell MB, Rodriguez M, Poirier T, et al. Cultural competency in health care and its implications for pharmacy, part 3a: emphasis on pharmacy education curriculums and future directions. Pharmacother. 2013;33(12):e347-e367.

4. Armstrong K, Ravenell KL, McMurphy S, Putt M. Racial/ethnic differences in physician distrust in the United States. Am J Pub Health. 2007 Jul;97(7):1283-1289.

5. Boulware LE, Cooper LA, Ratner LE, LaVeist TA, Powe NR. Race and trust in the health care system. Pub Health Reports. 2003;118(4):358-365.

6. Saha S, Komaromy M, Koepsell TD, Bindman AB. Patientphysician racial concordance and the perceived quality and use of health care. Arch Int Med. 1999 May 10;159(9):997-1004.

7. Street RL, O'Malley KJ, Cooper LA, Haidet P. Understanding concordance in patient-physician relationships: personal and ethnic dimensions of shared identity. Annals Fam Med. 2008 May 1;6(3):198-205.

8. Levy R, Like RC, Shabsin H. Origins and Strategies for Addressing Ethnic and Racial Disparities in Pharmaceutical Therapy: The Health-Care System, the Provider, and the Patient. Washington, DC: National Minority Quality Forum; 2009.

9. Centers for Disease Control and Prevention. Health disparities. https://www.cdc.gov/healthyyouth/disparities/index.htm. Accessed March 6, 2020.

10. Wall AL, Aljets A, Ellis SC, et al. White paper on pharmacy admissions: developing a diverse work force to meet the health-care needs of an increasingly diverse society. Am J Pharm Educ. 2015;79(7):S7.

11. Bush AA, McLaughlin JE, White C. A review of contemporary diversity literature in pharmacy education. Am J Pharm Educ. 2017;81(7):Article 5961.

12. Hayes B. Increasing the representation of underrepresented minority groups in US colleges and schools of pharmacy. Am J Pharm Educ. 2008;72(1):14.

13. Yanchick VA, Baldwin JN, Bootman JL, Carter RA, Crabtree BL, Maine LL. Report of the 2013-2014 Argus Commission: diversity and inclusion in pharmacy education. Am J Pharm Educ. 2014;78(10):S21.

14. American Association of Colleges of Pharmacy. 2016-2017 Profile of Pharmacy Students. https://www.aacp.org/sites/default/files/201805/fall-2017-profile $\% 20$ of $\% 20$ pharmacy $\% 20$ students-applications.pdf. Accessed March 6, 2020.

15. United States Census Bureau. Quick Facts, North Carolina. https://www.census.gov/quickfacts/nc. Accessed March 6, 2020. 16. University of North Carolina. Class Profile, 2018. https:// admissions.unc.edu/apply/class-profile-2/. Accessed March 6, 2020. 17. UNC Eshelman School of Pharmacy. Factbook and Benchmarks. https://pharmacy.unc.edu/about/ospa/factbook-and-benchmarks/. Accessed March 6, 2020.
18. Formicola A, Bailit H, D'Abreu K, et al. The dental pipeline program's impact on access disparities and student diversity. $J \mathrm{Am}$ Dent Assoc. 2009;140(3):346-353.

19. Saha S, Guiton G, Wimmers PF, Wilkerson L. Student body racial and ethnic composition and diversity-related outcomes in US medical schools. J Am Med Assoc. 2008;300(10):1135-45.

20. Valentine P, Wynn J, McLean D. Improving diversity in the health professions. NC Med J. 2016;77(2):137-140. doi:10.18043/ ncm.77.2.137.

21. Bush A. Same destination, different journey: towards a conceptual framework exploring URM students' experiences navigating pharmacy school. [in press June 6, 2019]. Am J Pharm Educ. doi 10.5688/ajpe7544.

22. Awe C, Bauman L. Theoretical and conceptual framework for a high school pathways to pharmacy program. Am J Pharm Educ. 2010;74(8): 149 .

23. White C, Conway JM, Davis PK, et al. AACP special taskforce white paper on diversifying our investment in human capital. Am J Pharm Educ. 2017;81(8):S13.

24. White C, Louis B, Persky A, et al. Institutional strategies to achieve diversity and inclusion in pharmacy education. Am J Pharm Educ. 2013;77(5):97.

25. Friedman A, Bush A, Melendez C, Lai S, McLaughlin JE. The young innovators program at the Eshelman institute for innovation: a case study examining the role of a professional pharmacy school in enhancing stem pursuits among secondary school students. Int $J$ STEM Educ. 2017;4(17):1-7.

26. McLaughlin JE, Bush A, Anderson J, Corbat J, Lai, S. Immersive pharmaceutical sciences research training for high school students through the Young Innovators Program. Am J Pharm Educ, 20017;82(5):7158.

27. American Association of Colleges of Pharmacy. Student Applications, Enrollments, and Degrees Conferred Reports. https:// www.aacp.org/research/institutional-research/student-applicationsenrollments-and-degrees-conferred. Accessed March 6, 2020.

28. US Department of Education. Office of Planning, Evaluation and Policy Development and Office of the Under Secretary. Advancing Diversity and Inclusion in Higher Education. https://www2.ed.gov/ rschstat/research/pubs/advancing-diversity-inclusion.pdf. Published 2016. Accessed March 6, 2020.

29. Swail WS. Retaining Minority Students in Higher Education: A Framework for Success. ASHE-ERIC Higher Education Report. Jossey-Bass, San Francisco, CA; 2003.

30. Quaye SJ, Harper SR, eds. Student Engagement in Higher Education: Theoretical Perspectives and Practical Approaches for Diverse Populations. Routledge; 2014.

31. Park JJ. Race on Campus: Debunking Myths with Data. Harvard Education Press. Cambridge, MA; 2018.

32. Harper SR, Hurtado S. Nine themes in campus racial climates and implications for institutional transformation. New Dir Student Serv. 2007 Dec;2007(120):7-24.

33. Patton LD, Bondi S. Nice white men or social justice allies? using critical race theory to examine how white male faculty and administrators engage in ally work. Race Ethnicity Educ. 2015; Jul 4;18(4):488-514.

34. Anonymous. Guide to allyship. http://www.guidetoallyship.com. Accessed March 6, 2020. 